\title{
Hyperalaninemia with Pyruvicemia due to Pyruvate Carboxylase Deficiency of the Liver
}

\author{
Toshio Yoshida, Keiya Tada, Tasuke Konno \\ and Tsuneo Arakawa \\ Department of Pediatrics (Prof. T's. Arakawa), \\ Faculty of Medicine, Tohoku University, Sendai
}

\begin{abstract}
A 10-year-old girl with mental retardation, hyperalaninemia and pyruvicemia was described. Studies on liver biopsy specimens from this patient revealed that pyruvate carboxylase activity was markedly decreased, whereas both pyruvate decarboxylation and glutamio pyruvic transaminase were normal in activity. Furthermore, it was found that an incorporation of pyruvate-2.14 $\mathrm{C}$ into glycogen in the liver was markedly diminished in the patient as compared with that in a control.

These findings suggest that the metabolic lesion in the patient with hyperalaninemia and pyruvicemia is a defective activity of pyruvate carboxylase of the liver, leading to an impaired gluconeogenesis.
\end{abstract}

In a preliminary report of ours, ${ }^{1}$ a mentally retarded girl with hyperalaninemia and pyruvicemia was presented and a defect of pyruvate carboxylase activity of the liver was demonstrated as a primary lesion of this illness.

The present paper deals with details of clinical and biochemical findings, including results of an investigation on gluconeogenesis, of this patient.

\section{Case Report}

M.O., a 10-year-old girl was referred to the University Hospital on June 13, 1968 , because of detailed examination for mental retardation. Her parents were not consanguineous. There were two siblings; one elder sister was also retarded mentally and died when 5 years old, another elder sister being healthy and of normal intelligence.

The patient was born after an uneventful pregnancy and full-term delivery. There was no abnormality in her neonatal history. Her mental and physical development was retarded; she smiled at the age of 18 months, held the head steadily at 1 year and was able to sit up alone at 4 years. Since 8 years of age, she had been admitted to an Institution for Retarded Children, Nishitaga, Sendai, then referred to the University Hospital for further investigation.

On admission when 10 years old, physical examination revealed a well nourished girl with apathetic countenance. She could not walk alone and could

Received for publication, May 31, 1969. 
speak nothing. Body weight was $20 \mathrm{~kg}$ (normal, $19.4 \mathrm{~kg}$ ) and circumference of the head was $48 \mathrm{~cm}$ (normal, $51.9 \mathrm{~cm}$ ). The lungs and heart were clear on auscultation. The liver and spleen were not palpable. Extremities were somewhat rigid and deep tendon reflexes were decreased on both sides. Pathological reflexes were not elicited.

Laboratory findings: Routine urinalysis revealed no abnormality. Serum electrolytes, lipids and protein were normal. Hematologic study showed that red cell count was $364 \times 10^{4} / \mathrm{cmm}$; hemoglobin, $12.1 \mathrm{~g} / 100 \mathrm{ml}$; hematocrit, $37.0 \%$; and white blood cell count, $9,450 / \mathrm{cmm}$. Bone marrow findings were not contributory. Liver function tests revealed no abnormality. Fasting blood glucose was $80 \mathrm{mg} / 100 \mathrm{ml}$.

Serum urea-nitrogen was $14.5 \mathrm{mg} / 100 \mathrm{ml}$, and uric acid was $3.8 \mathrm{mg} / 100 \mathrm{ml}$. Serum folic acid (L. casei) was $4.8 \mathrm{~m} \gamma / \mathrm{ml}$. Nonesterified fatty acid in serum was $3.09 \mathrm{mg} / 100 \mathrm{ml}$.

Blood gas analysis showed that; $\mathrm{pH}$ was $7.39 ; \mathrm{pO}_{2}, 90.1 \mathrm{~mm} \mathrm{Hg} ; \mathrm{pCO}_{2}, 20.7$ $\mathrm{mm} \mathrm{Hg}$; base excess, $-9.5 \mathrm{mEq} / \mathrm{L}$; standard bicarbonate, $17.2 \mathrm{mEq} / \mathrm{L}$; and buffer base, $40.9 \mathrm{mEq} / \mathrm{L}$.

Tryptophan loading test, ( $100 \mathrm{mg} / \mathrm{kg}$ of L-tryptophan), showed normal values in the urinary excretion of xanthurenic acid and pyridon; $0.4 \mu$ moles $/ \mathrm{kg}$ of bodyweight per 8 hours and $2.2 \mu$ moles $/ \mathrm{kg}$ of bodyweight per 8 hours, respectively.

Paperchromatography for urinary organic acids showed an excessive excretion of pyruvic acid, but the absence of a spot for methylmalonic acid.

Electroencephalography revealed a typical pattern of hypsarhythmia. Pneumoencephalography showed a dilatation of cerebral ventricles with the Evans' ratio of 0.52 . Ophthalmological examination revealed bilateral myopia.

Histological findings of the liver showed no abnormality.

TABLE 1. Serum amino acid levels (umoles/l) of our patient (M.O.)

\begin{tabular}{l|c|c}
\hline \multicolumn{1}{|c|}{ Amino acids } & Patient (M. O.) & Normal range $^{2}$ \\
\hline Threonine & 246 & $48-134$ \\
Serine & 515 & $216-699$ \\
Glutamine & 133 & $116-181$ \\
Proline & 127 & $62-289$ \\
Glutamic acid & 245 & $164-400$ \\
Glycine & 827 & $168-483$ \\
Alanine & 143 & $80-310$ \\
Valine & 38 & $8-25$ \\
Methionine & 46 & $29-90$ \\
Isoleucine & 79 & $73-164$ \\
Leucine & 54 & $37-97$ \\
Tyrosine & 43 & $28-125$ \\
Phenylalanine & 67 & $50-148$ \\
Lysine & 46 & $38-70$ \\
Histidine & 30 & Trace \\
Arginine & & -89 \\
& &
\end{tabular}


Analysis for amino acids in serum and urine: Thin layer chromatography of urinary amino acids revealed a slight increase in alanine. Serum amino acid patterns, analyzed by an automatic amino acid analyzer, showed a definite increase in alanine (cf. Table 1). Serum alanine levels were found to be ranging from 562 to $899 \mu$ moles/L during the observation period of 10 months.

Serum alanine levels following an oral alanine loading (100 $\mathrm{mg}$ of alanine $/ \mathrm{kg}$ ) showed an almost normal clearance curve except for an elevated initial values (cf. Fig. 1).

Serum alanine levels of her mother and father were 259 and $432 \mu \mathrm{moles} / \mathrm{L}$, respectively.

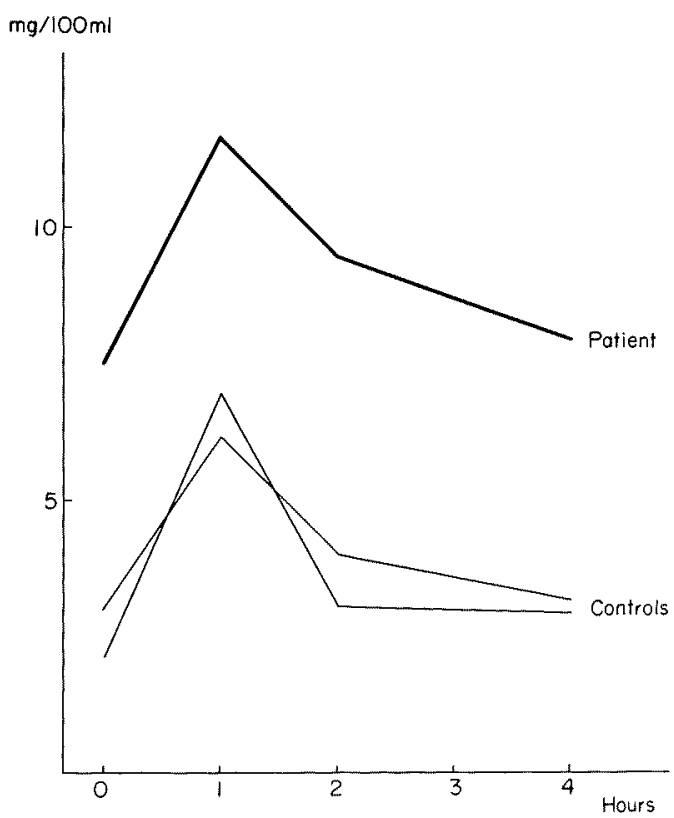

Fig. 1. Alanine tolerance curve in our patient (M.O.) and controls. Alanine (100 mg per $\mathrm{kg}$ of body weight) was given orally.

TABLE 2. Free amino acid pattern in the liver of our patient (M.O.) $(\gamma / g)$

\begin{tabular}{l|c|c}
\hline \multicolumn{1}{|c|}{ Amino acids } & Patient (M. O.) & Normal range $^{3}$ \\
\hline Aspartic acid & 75.0 & $25.1-113.0$ \\
Threonine & 86.0 & $20.6-89.0$ \\
Serine & 214.5 & $31.5-268.0$ \\
Glutamine & & \\
Glutamic acid & 252.0 & $57.4-454.0$ \\
Glycine & 82.3 & $22.8-118.0$ \\
Alanine & 259.0 & $23.3-184.0$ \\
Valine & 17.6 & $6.8-63.6$ \\
Methionine & 16.1 & $3.7-22.2$ \\
Isoleucine & 20.7 & $6.8-28.3$ \\
Leucine & 35.0 & $7.8-40.4$ \\
Tyrosine & 14.3 & $2.8-21.4$ \\
Phenylalanine & 23.6 & $4.4-25.6$
\end{tabular}


TABLE 3. The glutamic pyruvic transaminase (GPT) activity of the liver and leucocytes of our patient (M.O.)

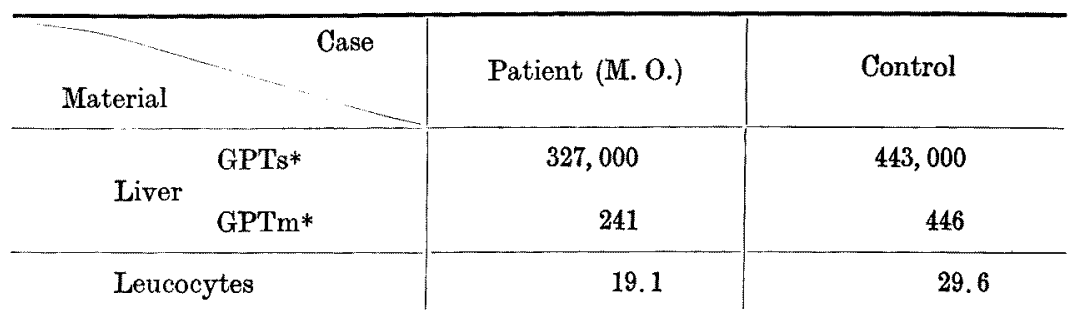

Unit is expressed as Karmen unit/g of wet weight of liver and Karmen unit/ $10^{\mathrm{B}}$ of leucocytes.

* GPTs stands for GPT in soluble fraction, GPTm for GPT in mitochondria.

TABLE 4. Blood pyruvate and lactate levels of our patient (M.O.)

\begin{tabular}{r|c|c}
\hline & $\begin{array}{c}\text { Pyruvate } \\
(\mathrm{mg} / 100 \mathrm{ml})\end{array}$ & $\begin{array}{c}\text { Lactate } \\
(\mathrm{mg} / 100 \mathrm{ml})\end{array}$ \\
\hline 1968, July 15 & 2.9 & 16.6 \\
Aug. 19 & 4.1 & 16.9 \\
Oct. 9 & 3.2 & 14.3 \\
Dec. 5 & 3.9 & 8.3 \\
1969, Feb. 26 & 2.7 & 23.5 \\
Mar. 28 & 3.8 & 36.4 \\
\hline Normal range & $0.5-1.5$ & $5-20$ \\
\hline
\end{tabular}

TABLE 5. Lactic acid formation from glucose by erythrocytes $(\gamma$ per $100 \mathrm{mg}$ of hemoglobin)

\begin{tabular}{ccc}
\hline Patient (M. O.) & 143 \\
\hline Controls & 1 & 147 \\
& 2 & 115
\end{tabular}

Note: $1.0 \mathrm{ml}$ of washed erythrocytes was incubated with $1.0 \mathrm{ml}$ of isotonic saline phosphate buffer (pH 7.4) containing $300 \mathrm{mg} / 100 \mathrm{ml}$ of glucose and 500 units per $\mathrm{ml}$ of water soluble penicillin at $37^{\circ} \mathrm{C}$ for 2 hours. Before and after the incubation, the content of lactic acid in the mixture was determined by Barker-Summerson's method."

Free amino acid pattern in the liver specimen obtained by a percutaneous biopsy showed a marked increase in alanine (cf. Table 2).

The glutamic pyruvic transaminase activity of the liver from the patient was found to be normal (cf. Table 3).

Blood pyruvate and lactate were estimated by Friedeman's method ${ }^{3}$ and Barker-Summerson's method, ${ }^{4}$ respectively. The blood pyruvate was found to be constantly elevated with a range from 2.9 to $4.1 \mathrm{mg}$ per $100 \mathrm{ml}$, and the blood lactate also tended to remain in a high level, ranging from 16.6 to $36.4 \mathrm{mg}$ per 100 ml (cf. Table 4).

The lactic acid formation from glucose was investigated by using erythrocytes. There was no difference in the in vitro lactate production from glucose by erythrocytes between the patient and controls (cf. Table 5). 
Decarboxylation of pyruvate and pyruvate carboxylase activity in the liver: Decarboxylation of pyruvate was assayed by determining the ${ }^{14} \mathrm{CO}_{2}$ formation from pyruvate-1 ${ }^{14} \mathrm{C}$, and the result showed no difference in decarboxylation of pyruvate between the patient and controls (cf. Table 6).

Pyruvate carboxylase activity was assayed by determining the incorporation of ${ }^{14} \mathrm{CO}_{2}$ to oxalacetate according to the method of Utter and $\mathrm{Keech},{ }^{5}$ and the results revealed that the pyruvate carboxylase activity was markedly decreased in the patient's liver (cf. Table 7).

Investigation on gluconeogenesis in the liver: After a 24-hour-fast liver specimens were obtained by the needle biopsy from this patient and a control subject without hepatic involvement. The assay for glycogen synthesis was carried out according to Hiatt et al.'s method ${ }^{6}$ with a slight modification: One $\mathrm{ml}$ of the Krebs-Ringer bicarbonate buffer containing $0.022 \mathrm{M}$ of lactate, $0.016 \mathrm{M}$ of pyruvate, $2 \mu \mathrm{c}$ of pyruvate- $2-{ }^{14} \mathrm{C}$ and liver slices (approximately $25 \mathrm{mg}$ in wet weight), was incubated at $37^{\circ} \mathrm{C}$ in an atmomosphere consisting of 95 per cent $\mathrm{O}_{2}$ and 6 per cent $\mathrm{CO}_{2}$. After incubated for 15 minutes and 30 minutes, glycogen was separated by Bergstrom et al.'s method.? The results showed a markedly diminished rate of incorporation of pyruvate- $2-{ }^{14} \mathrm{C}$ into glycogen in the patient's liver than in a control's liver (cf. Table 8).

TABLE 6. Activities of pyruvate decarboxylation in the liver from our patient (M.O.) and controls (103 cpm per $g$ of wet weight)

\begin{tabular}{lrl}
\hline & Patient (M. O.) & 149 \\
\hline Controls & 1 & 234 \\
& 2 & 147
\end{tabular}

Liver slices were incubated with pyruvate-1-14 $\mathrm{C}(0.1 \mu \mathrm{c} / \mu$ mole $)$ and Krebs-Ringer phosphate buffer for $60 \mathrm{~min}$ at $37^{\circ} \mathrm{C}$ and ${ }^{14} \mathrm{CO}_{2}$ liberated was determined.

TABLE 7. Activities of pyruvate carboxylase of the liver from our patient (M.O.) and controls

\begin{tabular}{lrr|c|c}
\hline & & $\begin{array}{c}\mu \text { moles per g of } \\
\text { wet weight }\end{array}$ & $\begin{array}{c}\mu \text { mole per mg } \\
\text { of protein }\end{array}$ \\
\hline Patient (M.O.) & $(10 \mathrm{y})$. & 0.19 & 0.0042 \\
Controls & 1 & $(5 \mathrm{y})$. & 1.16 & 0.0368 \\
& $\mathbf{2}$ & $(14 \mathrm{y})$. & 0.87 & 0.0264 \\
$\mathbf{3}$ & $(7 \mathrm{y})$. & 0.69 & 0.0214
\end{tabular}

TABLE 8. An incorporation of pyruvate-2.14C into glycogen of the liver $\left(10^{3} \mathrm{cpm}\right.$ per $g$ of wet weight)

\begin{tabular}{c|r|c}
\hline & $\begin{array}{r}\text { Patient } \\
\text { (M.O.) }\end{array}$ & Control \\
\hline Incubation time & 7.9 & 24.9 \\
$15 \mathrm{~min}$ & 10.2 & 189.2 \\
$30 \mathrm{~min}$ &
\end{tabular}

The rate of gluconeogenesis was expressed as cpm of ${ }^{14} \mathrm{C}$ incorporated to glycogen from pyruvate-2-14C. 


\section{Comment}

Hyperalaninemia with pyruvicemia was first reported by Lonsdale ${ }^{8}$ in 1968, who described a six-year-old boy with recurrent episodes of cerebellar ataxia and high serum levels of both alanine and pyruvate. However, the site of biochemical lesion of this disorder had remained unsolved at that time.

The present study of ours revealed that hyperalaninemia with pyruvicemia in a mentally retarded girl was due to a defect in the pyruvate carboxylase activity of the liver and that the defective activity of pyruvate carboxylase in the liver was also supported by a demonstration of a decreased rate of incorporation of pyruvate$2-\mathrm{C}^{14}$ into glycogen in the liver from this patient (cf. Fig. 2).

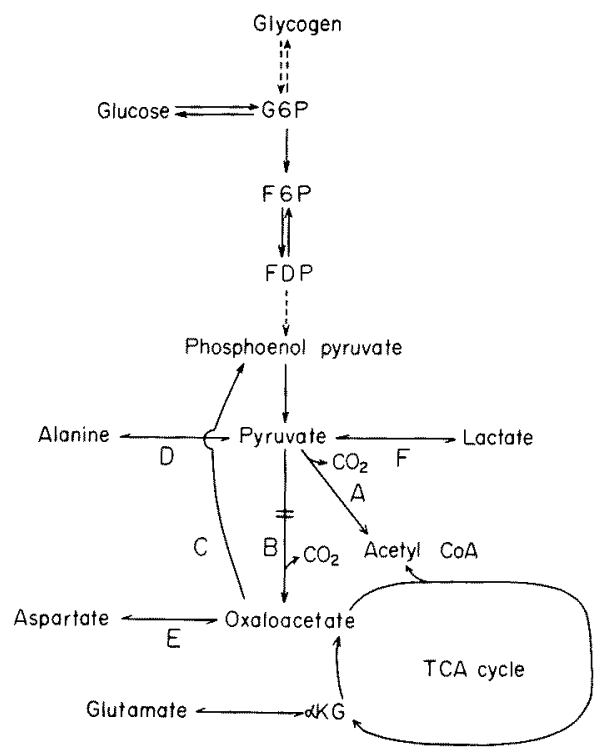

Fig. 2. The glycolytic and gluconeogenic pathways.
A: Pyruvate decarboxylation
B: Pyruvate carboxylase
C: Phosphoenol pyruvate carboxykinase D: GPT (Glutamic pyruvic transaminase)
E: GOT (Glutamic oxalacetic transaminase)
F: LDH (Lactic dehydrogenase)
$=$ Biochemical lesion in our patient

In 1962 Hartman et al. ${ }^{9}$ reported a case with lactic acidosis of unknown cause. Since then about 10 patients with idopathic hyperlacticacidemia have been reported and these patients showed a similarity in clinical features such as attacks of tachypena, convulsion, lethargy, muscular hypotonia, psychromotor retardation and obesity, and in all the patients there were signs of recurrent or chronic acidosis with an increase in both lactate and pyruvate in blood.

As for the biochemical mechanism responsible for lactic acidosis in these cases, no clearcut explanation has been described except that Schärer et al. ${ }^{10}$ suggested that the biochemical lesion might be at the level of pyruvate oxidation.

In 1968 Hommes et $a l .{ }^{11}$ made a biochemical study upon a patient with Leigh's 
encephalomyelopathy (subacute necrotizing encephalomyelopathy) and found a defective activity of pyruvate carboxylase in the liver of this patient. Further more, according to Hommes et al., blood lactate and pyruvate levels of this patient were $30.4 \mathrm{mg}$ and $4.4 \mathrm{mg}$ per $100 \mathrm{ml}$, respectively, with a somewhat low fasting levels of blood glucose, but there was no description on serum alanine levels.

The elevation of pyruvate and lactate in blood was reported in some cases of methylmalonic aciduria. ${ }^{13}$ Oberholzer et al. ${ }^{14}$ postulated that the elevation of blood pyruvate in cases with methylmalonic aciduria might be due to an inhibiting effect of methylmalonyl-CoA upon pyruvate carboxylase. In our patient with hyperalaninemia and pyruvicemia an excessive amount of methylmalonic acid was not detected in urine.

It may be, therefore, said that there is a possibility that among cases of chronic lactic acidosis reported so far, some may be identical with hyperalaninemia with pyruvicemia ${ }^{8}$ or with methylmalonic acidemia. ${ }^{14}$

Furthermore it remains unsolved whether or not hyperalaninemia with pyruvicemia and Leigh's encephalomyelopathy may be included into a same entity characterized by a defective activity of the pyruvate carboxylase in the liver.

\section{References}

1) Tada, K., Yoshida, T., Konno, T., Wada, Y., Yokoyama, Y. \& Arakawa, Ts. Hyperalaninemia with pyruvicemia (Preliminary report). Tohoku J. exp. Med., 1969, 97, $99-100$.

2) Tada, K. Serum amino acid pattern in normal children, assayed by automatic amino acid analyzer. Rinshoshoniigaku (Jap.), 1964, 12, 129-132.

3) Friedemann, T.E. \& Haugen, G.E. Pyruvic acid. I. Collection of blood for the determination of pyruvic and lactic acids. J. biol. Chem., 1942, 144, 67-77.

4) Barker, S.B. \& Summerson, W.H. The colorimetric determination of lactic acid in biological material. J. biol. Chem., 1941, 138, 535-554.

5) Utter, M.F. \& Keech, D.B. Pyruvate carboxylase. I. Nature of the reaction. $J$. biol. Chem., 1963, 238, 2603-2608.

6) Hiatt, H.H., Goldstein, M., Lareau, J. \& Horecker, B.L. The pathway of hexose synthesis from pyruvate in muscle. J. biol. Chem., 1958, 231, 303-307.

7) Bergstrom, J., Findor, J. \& Hultman, E. The contents of glycogen and potassium in human liver tissue obtained by needle biopsy. Scand. J. clin. Lab. Invest., 1961, 12, $353-354$.

8) Lonsdale, D. Hyperalaninemia with pyruvicemia. New Eng. J. Med., 1968, 278, 1235.

9) Hartmann, A.F., Wohltmann, H.J., Purkerson, M.L. \& Wesley, M.E. Lactate metabolism. Studies of a child with a serious congenital deviation. J. Pediat., 1962, 61, 165-180.

10) Schärer, K., Marty, A. \& Mühlethaler, J.P. Chronic congenital lactic acidosis. A fatal case with hyperphosphatemia and hyperlipemia. Helv. paediat. Acta, 1968, 23, 107-127.

11) Hommes, F.A., Polman, H.A. \& Reerink, J.D. Leigh's encephalomyelopathy: An inborn error of gluconeogenesis. Arch. Dis. Childh., 1968, 43, 423-426.

12) Leight, D. Subacute necrotizing encephalomyelopathy in an infant. J. Neurol. Neurosurg. Psychiat., 1951, 14, 216-221.

13) Lindblad, B., Lindblad, B.S., Olin, P., Svanberg, B. \& Zetterström, R. Methylmalonic acidemia. A disorder associated with acidosis, hyperglycinemia, and hyperlactatemia. Acta paediat. scand., 1968, 57, 417-424. 
14) Oberholzer, V.G. Burgess, E.A. \& Young, W.F. Methylmalonic aciduria. An inborn error of metabolism leading to chronic metabolic acidosis. Arch. Dis. Childh., 1967, 42, 492--504. 